ORIGINAL ARTICLE

\title{
Isolation, identification and oenological characterization of non-Saccharomyces yeasts in a Mediterranean island
}

\author{
G. Polizzotto ${ }^{1}$, E. Barone ${ }^{1}$, G. Ponticello ${ }^{1}$, T. Fasciana ${ }^{1,2}$, D. Barbera ${ }^{1}$, O. Corona ${ }^{3}$, G. Amore ${ }^{1}$, \\ A. Giammanco ${ }^{2}$ and D. Oliva ${ }^{1}$ \\ 1 Regional Institute of Wine and Oil, Palermo, Italy \\ 2 Department of Sciences for Health Promotion and Mother-Child Care 'G. D' Alessandro', University of Palermo, Palermo, Italy \\ 3 Department of Agricultural Sciences and Forestry, University of Palermo, Palermo, Italy
}

Significance and Impact of the Study: In recent years, interest is growing for wine production by nonSaccharomyces yeasts, both in research and in the industry. This study describes the yeast population of the grapes in a small-secluded island in the Mediterranean Sea, useful site for the search of new strains. Evaluation of fundamental oenological characters identifies potential best yeasts to assay in experimental vinifications. We also describe, for the first time, 14 new colony morphologies on WL Nutrient Agar, culture medium used to monitor the yeast population dynamics.

\author{
Keywords \\ diversity, identification, non-Saccharomyces, \\ wine, yeasts.

\section{Correspondence} \\ Daniele Oliva, Regional Institute of Wine and \\ Oil, via Libertà 66, 90143 Palermo, Italy. \\ E-mail: daniele.oliva@regione.sicilia.it \\ 2016/0690: received 1 April 2016, revised 30 \\ May 2016 and accepted 31 May 2016 \\ doi:10.1111/lam.12599
}

\begin{abstract}
We isolated, identified and characterized yeast strains from grapes, and their fermented musts, sampled in the small island of Linosa, where there are no wineries and therefore the possibility of territory contamination by industrial strains is minimal. By traditional culture-dependent methods, we isolated 3805 colonies, distinguished by molecular methods in 17 different species. Five hundred and fortyfour isolates were analysed for the main oenological characteristics such as fermentative vigour with and without sulphites, sugar consumption and production of alcohol, volatile acidity, hydrogen sulphide, glycerol and $\beta$-glucosidase. This analysis identified Kluyveromyces marxianus (seldomly used in winemaking) as the most interesting candidate yeast for the production of innovative wines.
\end{abstract}

\section{Introduction}

Non-Saccharomyces yeasts include several species responsible for the early stages of spontaneous alcoholic fermentation (Jolly et al. 2014). Grapes are the main source of non-Saccharomyces yeasts, with same species typically found worldwide (Jolly et al. 2006; Barata et al. 2012). In recent years, interest in these yeasts has been growing because they can improve wine quality: (i) lowering the alcohol content; (ii) increasing the final concentrations of glycerol; (iii) increasing the range of flavour compounds, through the production of esters, higher alcohols and $\beta$ glucosidase; (iv) producing proteolytic and pectinolytic activities; (v) affecting the concentration of polysaccharides (Jolly et al. 2014). For these reasons, researchers all over the world agree on the need to increase our knowledge of non-Saccharomyces yeasts and of their oenological characteristics (Ciani et al. 2010; Jolly et al. 2014; Steensels and Verstrepen 2014).
In the last years, yeast industry has started to produce selected non-Saccharomyces strains (Lu et al. 2016). However, the use of commercial yeasts can cause their dissemination, although limited, in the areas surrounding the wineries (Valero et al. 2005). In order to find new nonSaccharomyces yeast strains for wine production, we studied yeast population found on grapes in a small Mediterranean island, Linosa, where there are no wineries and where the possibility of yeast strains exchanges from other territories is limited.

\section{Results and discussion}

Yeast population

We report the yeast population found on grapes in two new vineyards (A and B) and in some old vines on the island of Linosa. This is a small, secluded island in the Mediterranean Sea (Fig. 1), where there are no cellars and 

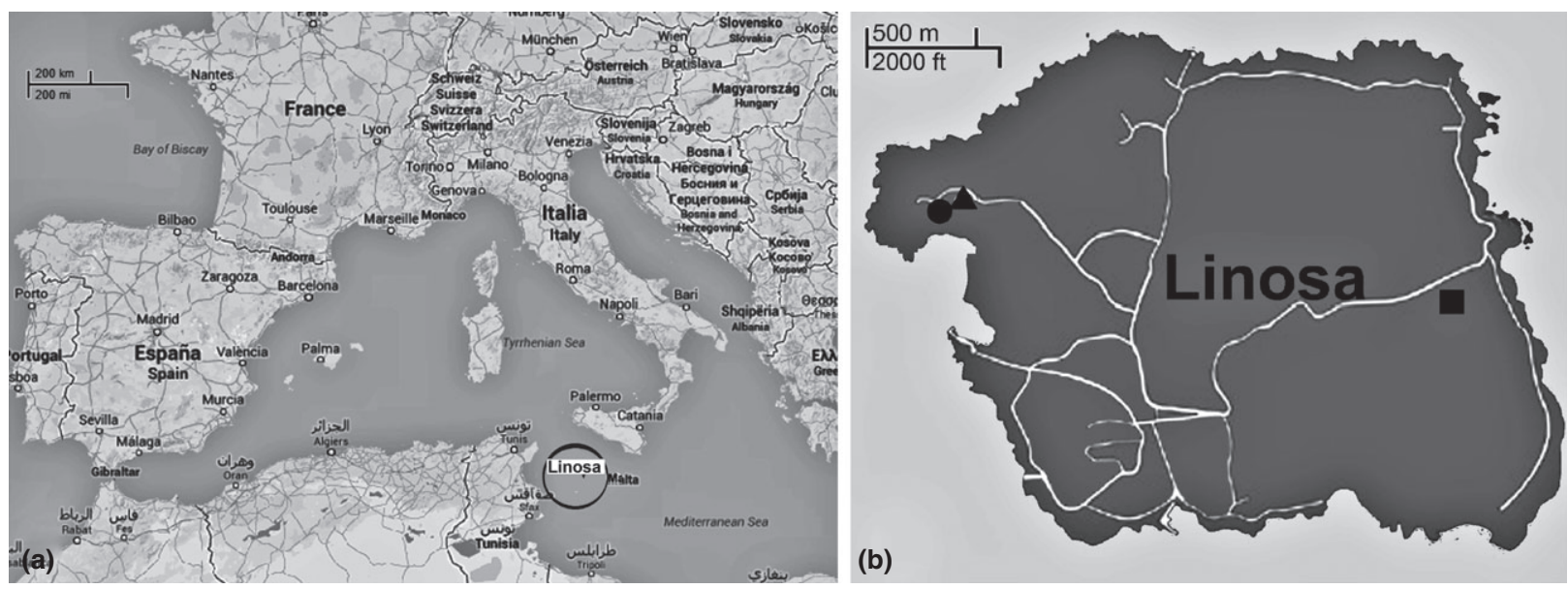

Figure 1 Geographic localization of the Linosa Island (a) and location of the grape sampling sites (b): new vineyard $A$, new vineyard $B$ and $(\mathbf{\Delta})$ old vines

no import of commercial yeasts, except for one Saccharomyces cerevisiae strain used in the only one bakery of the island. Although the introduction of yeast strains from outside remains possible, for example, via insects (Stefanini et al. 2012) or migratory birds (Francesca et al. 2012), we expected that the contamination by commercial yeasts would be lower in comparison to areas where wineries are present.

For an initial evaluation, a total of 3805 yeast colonies (from grapes and, to increase the ability to isolate any alcohol tolerant yeast, from their musts fermented in the laboratory) were analysed and divided into 16 different groups (Table 1, Fig. 2) on the basis of their morphotype on WL Nutrient agar, which allows a preliminary discrimination between yeast species by colony morphology and colour (Pallmann et al. 2001; Romancino et al. 2008; Li et al. 2011). To the best of our knowledge, except for the genus Hanseniaspora and the species Issatchenkia orientalis, the remaining colony morphologies of Table 1 have not been previously described.

The ITS rDNA of representative 553 isolates were analysed by PCR-RFLP (Table 1). We found distinctive restriction patterns for each of the 16 groups, except for morphotypes I and II, which showed the same patterns; moreover, morphotype IX was resolved into three different restriction patterns, for a total of 17 different patterns. The sequencing of D1/D2 region of the $26 \mathrm{~S}$ rDNA allowed the unequivocal identification of 15 species, while further tests were required in two cases of uncertainty. Morphotypes I and II were identified as two different varieties of yeast-like fungus Aureobasidium pullulans. PCR-RFLP patterns were consistent with at least one of the following authors: Esteve-Zarzoso et al. (1999), Granchi et al. (1999), Villa-Carvajal et al. (2006), Nisiotou and
Nychas (2007), Nisiotou et al. (2007), Barata et al. (2008), Jatmiko et al. (2012), Merín et al. (2013). Since in the region D1/D2 there are no differences between Kluyveromyces lactis var. lactis and Kluyveromyces marxianus, for morphology XIII further sequencing of the ITS region of rDNA was carried out. Results revealed only 92\% identity with $K$. lactis var. lactis (type strain CBS683, accession number AJ229069) and 100\% with K. marxianus (type strain CBS712, accession number EF568057), leading to the unequivocal assignment of this morphology to the latter species. Finally, since in the region D1/D2 there are no differences between Candida albicans and Candida africana, the phenotypic identification of morphology III has led to its unequivocal assignment to the species C. albicans which can occasionally be found on the grapes (Jolly et al. 2006).

We found most of the species only in samples from old vines; A. pullulans var. pullulans and Hanseniaspora opuntiae also in samples from vineyards A and B; Pichia norvegensis even in samples of the vineyard A; A. pullulans var. melanigenum, Cryptococcus albidus, Hanseniaspora uvarum and Kodamaea ohmeri only in samples from the vineyard $\mathrm{B}$, located on the opposite side of the island than the other two sampling sites. The greatest biodiversity found on old vines is probably due to lack of phytosanitation and/or to the increased accessibility of the grapes to the animals of the island, due to the lack of fences.

Table 1 also shows that we found most of the yeasts only or mainly on grapes, with Hanseniaspora guilliermondii, $H$. opuntiae, $H$. uvarum and $I$. orientalis the most abundant species. We recovered A. pullulans var. pullulans, $H$. guilliermondii and $H$. opuntiae from samples at all stages of ripeness; the occurrence of all the other species was restricted to specific times during grape maturation. 


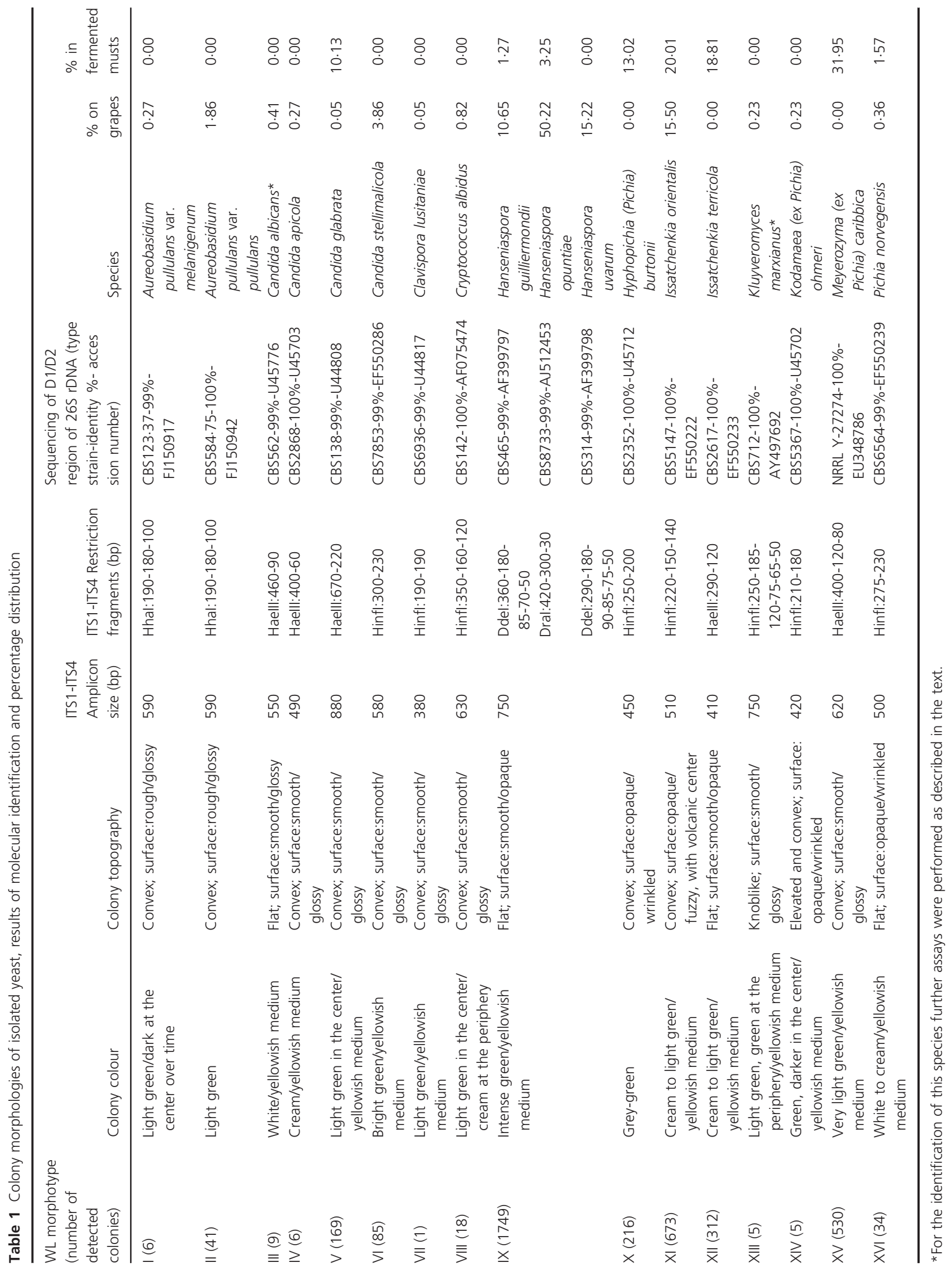



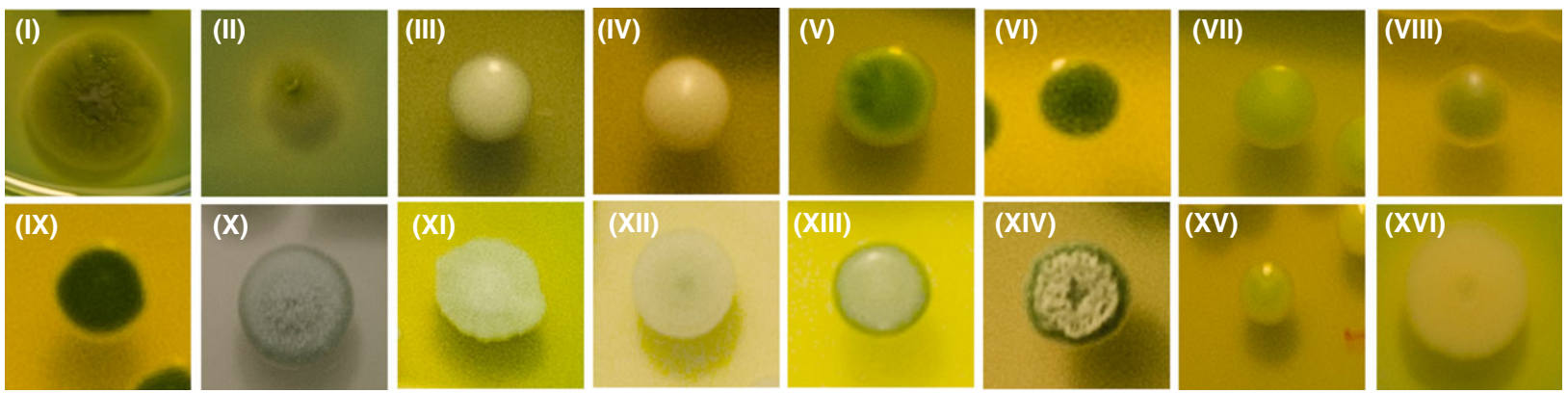

Figure 2 The 16 colony morphotypes on WL Nutrient Agar. I: Aureobasidium pullulans var. melanigenum; II: Aureobasidium pullulans var. pullulans; III: Candida albicans; IV: Candida apicola; V: Candida glabrata; VI: Candida stellimalicola; VII: Clavispora lusitaniae; VIII: Cryptococcus albidus; IX: Hanseniaspora spp.; X: Hyphopichia (Pichia) burtonii; XI: Issatchenkia orientalis; XII: Issatchenkia terricola; XIII: Kluyveromyces marxianus; XIV: Kodamaea (ex Pichia) ohmeri; XV: Meyerozyma (ex Pichia) caribbica; XVI: Pichia norvegensis.

Since the opportunistic pathogenicity of C. albicans is well known (Papon et al. 2013), all the nine isolates of this species were eliminated and we did not carry out further investigations on them.

\section{Oenological characterization of the yeast species}

Overall, 10 important oenological characteristics were assayed on 544 isolates belonging to the remaining 16 species: results of the analysis for eight of these parameters are shown in Table 2; measured values for a strain of S. cerevisiae and for unfermented must are also shown respectively as positive and negative control. Fermentative vigour without sulphites after two and 7 days, residual reducing sugar and ethanol produced after 15 days are all indicators of the fermentative ability of the different yeasts (Caridi et al. 2002; Luna-Solano et al. 2003). As expected, all the non-Saccharomyces yeasts isolated in Linosa show fermentative ability lower than S. cerevisiae. In addition, if we take into account the amounts of fermented sugar, they are higher producers of volatile acidity compared to S. cerevisiae, with the largest amount ever produced by the genus Hanseniaspora. Furthermore, as demonstrated by the differences in the fermentative vigour without and with $\mathrm{SO}_{2}$, except Candida glabrata, they are all sensitive to sulphites, a preservative widely used in winemaking. Four species, Candida apicola, C. glabrata, I. orientalis and $K$. marxianus, ferment sugar quantities between 65 and $91 \mathrm{~g} \mathrm{l}^{-1}$ and produce alcohol between $3.76 \%$ and $5.39 \%(\mathrm{v} / \mathrm{v})$. Three of them (C. apicola, C. glabrata and I. orientalis) produce significant amounts of glycerol: this compound, above certain thresholds, can positively contribute to the taste, smoothness, consistency and overall body of wine (Scanes et al. 1998). In particular, C. apicola yeasts isolated in Linosa produce two and a half times more glycerol per gram of fermented sugar compared to the S. cerevisiae control strain.
Table 3 shows the production of $\mathrm{H}_{2} \mathrm{~S}$ and of $\beta$-glucosidase. Six species (including C. apicola and I. orientalis) produce high amounts of hydrogen sulphide, incompatible with their oenological use because above 50-80 $\mu \mathrm{g} \mathrm{l}^{-1}, \mathrm{H}_{2} \mathrm{~S}$ produces an off-flavour of rotten eggs (Rauhut 1993). However, several isolates of C. glabrata and K. marxianus produce quantities of sulphide compatible with winemaking. Table 3 shows also that isolates of $K$. marxianus found in Linosa are among the higher producers of $\beta$-glucosidase, an enzyme able to release monoterpenols, important in wine flavour and aroma, from their flavourless, nonvolatile glycosidic complexes (Jolly et al. 2014).

In conclusion, several isolates of the species C. glabrata and $K$. marxianus could be useful in the production of experimental wines richer, respectively, in glycerol and aromatic compounds. The presence of C. glabrata on grapes and musts has been widely reported (see Jolly et al. 2006 for review), but its possible pathogenicity and resistance to azoles and polyenes (Papon et al. 2013) make its use impossible in winemaking (EFSA 2013). Kluyveromyces marxianus has instead a much lower pathogenicity, is sensitive to antimycotics (Papon et al. 2013) and has a qualified presumption of safety (EFSA, European Food Safety Authority 2013). This microorganism has been isolated from a large variety of habitats, mostly from foods and beverages, especially dairy products, as well as decaying plant tissue and associated insects (Lachance 2011). It is widely studied for its ability to produce enzymes of industrial interest as inulinase, $\beta$-galactosidase, $\beta$-glucosidase, endopolygalacturonases, protein phosphatases, carboxypeptidases and aminopeptidases (Fonseca et al. 2008), but its direct use in winemaking has been very limited so far (Kourkoutas et al. 2004). Thanks to their fermentative ability and $\beta$-glucosidase activity, K. marxianus yeasts isolated in Linosa may therefore represent an important starting point for the production of new and more aromatic wines. 


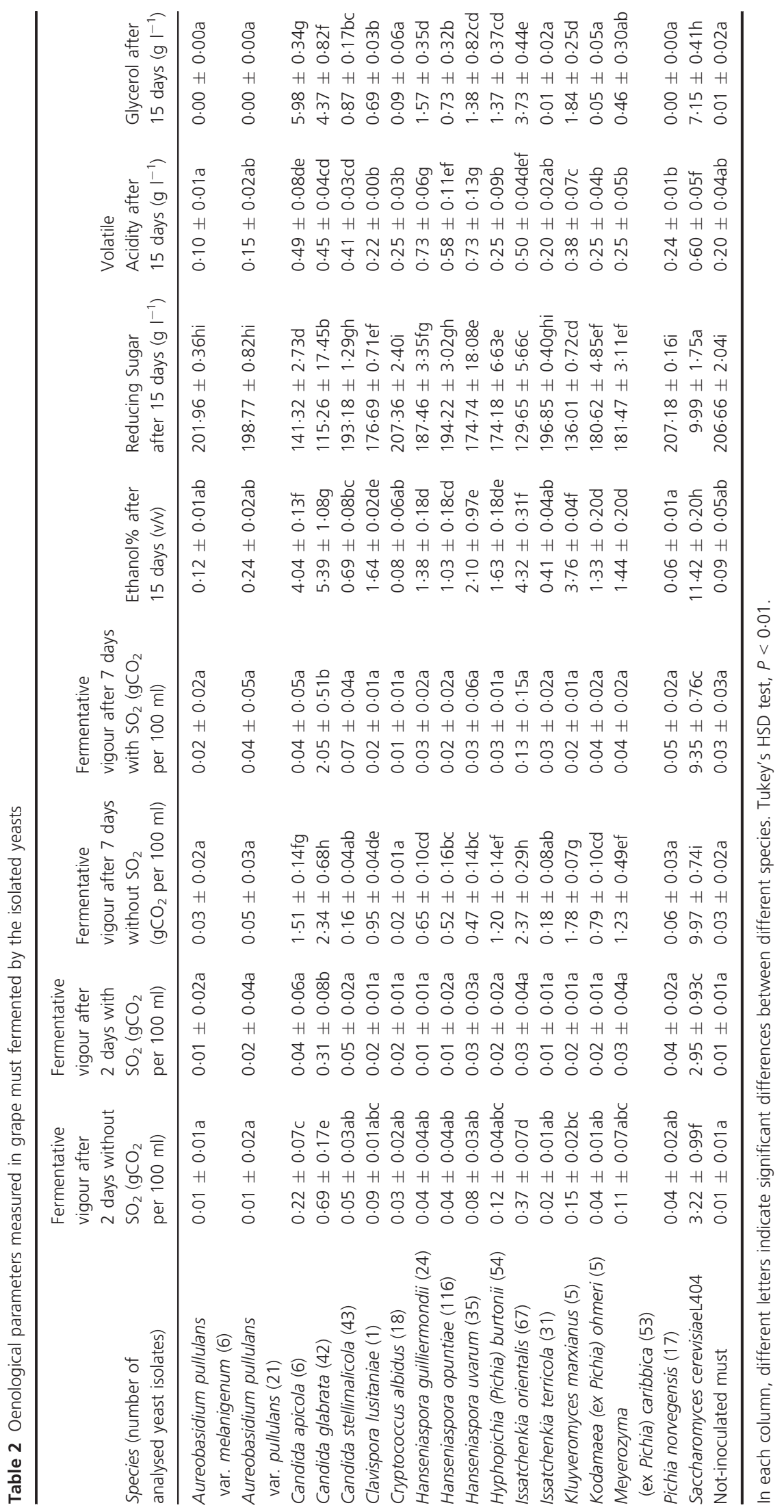


Table 3 Distribution of yeast isolates in scales from zero to three and from white to black, respectively, for $\beta$-glucosidase and sulphide increasing production

\begin{tabular}{|c|c|c|c|c|c|c|c|c|c|}
\hline \multirow[b]{2}{*}{ Species } & \multicolumn{4}{|c|}{$\beta$-glucosidase } & \multicolumn{5}{|c|}{$\mathrm{H}_{2} \mathrm{~S}$ production } \\
\hline & 0 & 1 & 2 & 3 & w & ph & $\mathrm{h}$ & dh & $\mathrm{b}$ \\
\hline Aureobasidium pullulans var. melanigenum & & & 6 & & & 6 & & & \\
\hline Aureobasidium pullulans var. pullulans & & & 14 & 7 & 21 & & & & \\
\hline Candida apicola & & & 6 & & & & & 6 & \\
\hline Candida glabrata & 42 & & & & & 38 & & 4 & \\
\hline Candida stellimalicola & & 36 & & 7 & 32 & 7 & & 4 & \\
\hline Clavispora lusitaniae & & 1 & & & & & & 1 & \\
\hline Cryptococcus albidus & & & 18 & & 18 & & & & \\
\hline Hanseniaspora guilliermondii & & & 24 & & & 24 & & & \\
\hline Hanseniaspora opuntiae & & & 116 & & 2 & 114 & & & \\
\hline Hanseniaspora uvarum & & & 34 & 1 & 31 & 4 & & & \\
\hline Hyphopichia (Pichia) burtonii & & & & 54 & & & & 54 & \\
\hline Issatchenkia orientalis & 67 & & & & & & & 67 & \\
\hline Issatchenkia terricola & & 31 & & & & & & & 31 \\
\hline Kluyveromyces marxianus & & & & 5 & & & 5 & & \\
\hline Kodamaea (ex Pichia) ohmeri & & & 5 & & & & & 5 & \\
\hline Meyerozyma (ex Pichia) caribbica & & 51 & 2 & & & 28 & 24 & 1 & \\
\hline Pichia norvegensis & & 17 & & & & 3 & & 14 & \\
\hline
\end{tabular}

W, white; ph, pale hazel; h, hazel; dh, dark hazel; b, black.

\section{Materials and methods}

\section{Sampling sites}

In 2007, we established two experimental vineyards (A and $\mathrm{B}$ ) of the Muscat of Alexandria cultivar on Linosa island (433 inhabitants; $5.43 \mathrm{~km}^{2} ; \quad 35^{\circ} 52^{\prime} 00^{\prime \prime}$ North; $12^{\circ} 52^{\prime} 00^{\prime \prime}$ East; Fig. 1a), about $160 \mathrm{~km}$ away from Tunisia and Sicily (Italy). We used Bordeaux mixture for phytosanitation and protected the vineyards with fences. Some unprotected scattered plants of Ansonica cultivar were also present (Fig. 1b); we did not applied any phytosanitation treatment to these 'old vines'.

\section{Grape sampling}

During 2009 summer, we carried out aseptically five samplings in duplicate, once every 2 weeks, from each vineyard and from the old vines. Samples were kept cold and transferred to the laboratory within $12 \mathrm{~h}$.

\section{Microbiological analyses of 'grapes' and 'fermented musts'}

One hundred millilitres of grape juices was poured into sterile bottles and left to ferment at $28^{\circ} \mathrm{C}$ ('fermented musts') until no further effervescence could be seen and no further reduction in glucose concentration was measured using a Keto Diabur Test (Roche, Mannheim,
Germany). We plated aliquots of grape juices and fermented musts, eventually serially diluted in duplicate with sterile peptone $1 \mathrm{~g} \mathrm{l}^{-1}$, on WL Nutrient Agar (Oxoid, Basingstoke, England) (Pallmann et al. 2001) and on Lysine Agar (Oxoid) (Fowell 1965), with Diphenyl $0 \cdot 1 \mathrm{~g} \mathrm{l}^{-1}$ to slow-down moulds (Kurtzman et al. 2011). After 5 days at $28^{\circ} \mathrm{C}$, we analysed plates with $20-200$ colonies. When the number of colonies from undiluted samples was low, we analysed a high number of plates. We streaked yeasts in single colonies on WL Nutrient Agar to better recognize their morphotypes. Based on colony morphology on WL Nutrient Agar and microscopic analyses (data not shown), morphotypes of 3805 yeast colonies were identified. A number of representative colonies were isolated and purified: 553 yeast isolates were stored at $4^{\circ} \mathrm{C}$ on Malt Agar (30 $\mathrm{g} \mathrm{l}^{-1}$ Malt extract, $15 \mathrm{~g} \mathrm{l}^{-1}$ Agar; Oxoid) and used for further investigations.

\section{Molecular analyses}

Five hundred and fifty-three yeast isolates were analysed by PCR-RFLP (Esteve-Zarzoso et al. 1999) using the primers ITS1 and ITS4 (White et al. 1990). We digested amplicons with HinfI, HaeIII, HhaI and, in case, DdeI and RsaI (New England BioLabs, Ipswich, MA, USA). The PCR products and their restriction fragments were separated on $1.5-3 \%$ agarose gels with 1 xTBE buffer; Table 1 shows only one polymorphism per species. One-four isolates per each group were analysed by amplification and 
sequencing of the D1/D2 region of the 26S rDNA (Kurtzman and Robnett 1997) using the primers NL-1 and NL-4 (O'Donnell 1993). Amplification and sequencing of the region ITS1-5.8S-ITS2 were performed using the primers ITS1 and ITS4 (White et al. 1990). Except for morphology IX, the D1/D2 sequence analysis along with the sequence analysis of the $K$. marxianus ITS region were performed at the Industrial Yeasts Collection (www.dbvpg.unipg.it) of the University of Perugia (Italy).

\section{Phenotypic identification}

For the unequivocal discrimination between C. africana and C. albicans, we assayed physiological (growth at $45^{\circ} \mathrm{C}$ ) and biochemical (assimilation of $N$-acetylglucosamine, threalose and DL-lactate) abilities in triplicate (Romeo and Criseo 2011). These assays were performed at the Industrial Yeasts Collection of the University of Perugia (Italy).

\section{Phenotypic characterization}

Fermentative vigour without and with sulphites were measured according to Caridi et al. (2002): flasks containing $100 \mathrm{ml}$ of sterile white must $\left(20^{\circ} \mathrm{Brix}, \mathrm{pH} 3.20\right.$, filtered by Stericup vacuum filtration system, Millipore, Billerica, MA, USA), with and without $\mathrm{SO}_{2}\left(100 \mathrm{mg} \mathrm{l}^{-1}\right)$ and covered with $10 \mathrm{ml}$ of sterile liquid paraffin to prevent evaporation, were inoculated in triplicate with $5 \mathrm{ml}$ of $48 \mathrm{~h}$ precultures of each isolated yeast and incubated at $25^{\circ} \mathrm{C}$. Fermentative vigour was measured as weight loss caused by $\mathrm{CO}_{2}$ production $\left(\mathrm{g} \mathrm{CO}_{2}\right.$ per $100 \mathrm{ml}$ ) after 2 and 7 days; S. cerevisiae L404 (DIPROVAL collection of the University of Bologna, Italy) was used as a positive control, not-inoculated must as negative control. Reducing sugar, ethanol, glycerol and volatile acidity were measured in must prepared as described above (without $\mathrm{SO}_{2}$ ) using a WineScan ${ }^{\mathrm{TM}}$ apparatus (FOSS, Hilleroed, Denmark) after 15 days of fermentation. We estimated $\mathrm{H}_{2} \mathrm{~S}$ production on BiGGY agar (Oxoid) recording the biomass colour after $48 \mathrm{~h}$ at $25^{\circ} \mathrm{C}$ (Nickerson 1953). $\beta$ glucosidase production was assayed as in Strauss et al. (2001) onto selective medium containing $6.7 \mathrm{~g} \mathrm{l}^{-1}$ Yeast Nitrogen Base (Difco, Detroit, MI, USA), $5 \mathrm{~g} \mathrm{l}^{-1}$ arbutin (Sigma-Aldrich, Saint Louis, MO, USA), $0 \cdot 2 \mathrm{~g} \mathrm{l}^{-1}$ ammonium ferric citrate and $20 \mathrm{~g} \mathrm{l}^{-1}$ agar ( $\mathrm{pH} 5 \cdot 0$ ).

\section{Statistical analysis}

We used Analysis of Variance (ANOVA) and Tukey's Honestly Significant Difference (HSD) test to calculate significant differences between oenological parameters of different yeast species reported in Table 2. All tests were performed at a significances level of $P<0.01$ using the statistical program sPSs (ver. 13, IBM, Armonk, NY, USA).

\section{Acknowledgements}

We thank Prof. Pietro Buzzini and Dr Benedetta Turchetti (Department of Agricultural, Food and Environmental Science, University of Perugia, Italy) for their professional support and critical reading of the manuscript. We are grateful to Mr Fedele Giardina for vineyards management and logistical help and to $\mathrm{Mr}$ Pietro Marchese for his important contribution in the preparation of the figures. An intramural grant of the RIWO provided the funds for this work.

\section{Conflict of Interest}

Under Italian law, the industrial property of the yeast strains described in this paper belong to D. Oliva and to the RIWO.

\section{References}

Barata, A., Seborro, F., Belloch, C., Malfeito-Ferreira, M. and Loureiro, V. (2008) Ascomycetous yeast species recovered from grapes damaged by honeydew and sour rot. J Appl Microbiol 104, 1182-1191.

Barata, A., Malfeito-Ferreira, M. and Loureiro, V. (2012) The microbial ecology of wine grape berries. Int J Food Microbiol 153, 243-259.

Caridi, A., Cufari, A. and Ramondino, D. (2002) Isolation and clonal pre-selection of enological Saccharomyces. J Gen Appl Microbiol 48, 261-267.

Ciani, M., Comitini, F., Mannazzu, I. and Domizio, P. (2010) Controlled mixed culture fermentation: a new perspective on the use of non-Saccharomyces yeasts in winemaking. FEMS Yeast Res 10, 123-133.

EFSA, European Food Safety Authority (2013) Scientific opinion on the maintenance of the list of QPS biological agents intentionally added to food and feed (2013 update). EFSA J 11, 3449.

Esteve-Zarzoso, B., Belloch, C., Uruburu, F. and Querol, A. (1999) Identification of yeasts by RFLP analysis of the $5.8 \mathrm{~S}$ rRNA gene and the two ribosomal internal transcribed spacers. Int J Syst Bacteriol 49, 329-337.

Fonseca, G.G., Heinzle, E., Wittmann, C. and Gombert, A.K. (2008) The yeast Kluyveromyces marxianus and its biotechnological potential. Appl Microbiol Biotechnol 79, 339-354.

Fowell, R.R. (1965) The identification of wild yeast colonies on Lysine Agar. J Appl Bacteriol 28, 373-383.

Francesca, N., Canale, D.E., Settanni, L. and Moschetti, G. (2012) Dissemination of wine-related yeasts by migratory birds. Environ Microbiol Rep 4, 105-112. 
Granchi, L., Bosco, M., Messini, A. and Vincenzini, M. (1999) Rapid detection and quantification of yeast species during spontaneous wine fermentation by PCR-RFLP analysis of the rDNA ITS region. J Appl Microbiol 87, 949-956.

Jatmiko, Y.D., De Barros Lopes, M. and Barton, M.D. (2012) Molecular identification of yeasts isolated from Dadih by RFLP-PCR and assessment on their ability in utilizing lactate. Microbiol Indones 6, 30-34.

Jolly, N.P., Augustyn, O.P.H. and Pretorius, I.S. (2006) The role and use of non-Saccharomyces yeasts in wine production. S Afr J Enol Vitic 27, 15-39.

Jolly, N.P., Varela, C. and Pretorius, I.S. (2014) Not your ordinary yeast: non-Saccharomyces yeasts in wine production uncovered. FEMS Yeast Res 14, 215-237.

Kourkoutas, Y., McErlean, C., Kanellaki, M., Hack, C.J., Marchant, R., Banat, I.M. and Koutinas, A.A. (2004) High-temperature wine making using the thermotolerant yeast strain Kluyveromyces marxianus IMB3. Appl Biochem Biotechnol 112, 25-35.

Kurtzman, C.P. and Robnett, C.J. (1997) Identification of clinically important Ascomycetous yeasts based on nucleotide divergence in the $5^{\prime}$ end of the large-subunit (26S) ribosomal DNA gene. J Clin Microbiol 35, 12161223.

Kurtzman, C.P., Fell, J.W., Boekhout, T. and Robert, V. (2011) Methods for isolation, phenotypic characterization and maintenance of yeasts. In The Yeasts, A Taxonomic Study ed. Kurtzman, C.P., Fell, J.W. and Boekhout, T. 5th ed. pp. 85-110. Amsterdam: Elsevier.

Lachance, M.A. (2011) Kluyveromyces van der Walt (1971). In The Yeasts, A Taxonomic Study ed. Kurtzman, C.P., Fell, J.W. and Boekhout, T. 5th ed. pp. 471-482. Amsterdam: Elsevier.

Li, E., Liu, A., Xue, B. and Liu, Y. (2011) Yeast species associated with spontaneous wine fermentation of Cabernet sauvignon from Ningxia, China. World J Microbiol Biotechnol 27, 2475-2482.

Lu, Y., Huang, D., Lee, P.R. and Liu, S.Q. (2016) Assessment of volatile and non-volatile compounds in durian wines fermented with four commercial non-Saccharomyces yeasts. J Sci Food Agric 96, 1511-1521.

Luna-Solano, G., Salgado-Cervantes, M.A., Ramirez-Lepe, M., Garcia-Alvarado, M.A. and Rodrigues-Jimenes, G.C. (2003) Effect of drying type and drying conditions over fermentative ability of brewer's yeast. J Food Process Eng 26, 135-147.

Merín, M.G., Mendoza, L.M. and Morata de Ambrosini, V.I. (2013) Pectinolytic yeasts from viticultural and enological environments: novel finding of Filobasidium capsuligenum producing pectinases. J Basic Microbiol 54, 835-842.

Nickerson, W. (1953) Reduction of inorganic substances by yeasts. I. Extracellular reduction of sulfite by species of Candida. J Infect Dis 93, 43-56.

Nisiotou, A.A. and Nychas, G.J. (2007) Yeast populations residing on healthy or Botrytis-infected grapes from a vineyard in Attica, Greece. Appl Environ Microbiol 73, 2765-2768.

Nisiotou, A.A., Spiropoulos, A.E. and Nychas, G.J. (2007) Yeast community structures and dynamics in healthy and Botrytis-affected grape must fermentations. Appl Environ Microbiol 73, 6705-6713.

O'Donnell, K. (1993) Fusarium and its near relatives. In The Fungal Holomorph: Mitotic, Meiotic and Pleomorphic Speciation in Fungal Systematics, ed. Reynolds, D.R. and Taylor, J.W. pp. 225-233. Wallingford: CAB International.

Pallmann, C.L., Brown, J.A., Olineka, T.L., Cocolin, L., Mills, D.A. and Bisson, L.F. (2001) Use of WL Medium to profile native flora fermentations. Am J Enol Vitic 52, 198-203.

Papon, N., Courdavault, V., Clastre, M. and Bennett, R.J. (2013) Emerging and emerged pathogenic Candida species: beyond the Candida albicans paradigm. PLoS Pathog 9, e1003550.

Rauhut, D. (1993) Yeasts - production of sulfur compounds. In Wine Microbiology and Biotechnology ed. Fleet, G.H. p. 200. Chur: Harwood Academic Publishers.

Romancino, D., Di Maio, S., Muriella, R. and Oliva, D. (2008) Analysis of non Saccharomyces yeast populations isolated from grape must from Sicily (Italy). J Appl Microbiol 105, 2248-2254.

Romeo, O. and Criseo, G. (2011) Candida africana and its closest relatives. Mycoses 54, 475-486.

Scanes, K.T., Hohmann, S. and Prior, B.A. (1998) Glycerol production by the yeast Saccharomyces cerevisiae and its relevance to wine: a review. S Afr J Enol Vitic 19, 17-22.

Steensels, J. and Verstrepen, K.J. (2014) Taming wild yeast: potential of conventional and nonconventional yeasts in industrial fermentations. Annu Rev Microbiol 68, 61-80.

Stefanini, I., Dapporto, L., Legras, J.L., Calabretta, A., Di Paola, M., De Filippo, C., Viola, R., Capretti, P. et al. (2012) Role of social wasps in Saccharomyces cerevisiae ecology and evolution. Proc Natl Acad Sci USA 109, 13398-13403.

Strauss, M.L., Jolly, N.P., Lambrechts, M.G. and van Rensburg, P. (2001) Screening for the production of extracellular hydrolytic enzymes by non-Saccharomyces wine yeasts. $J$ Appl Microbiol 91, 182-190.

Valero, E., Schuller, D., Cambon, B., Casal, M. and Dequin, S. (2005) Dissemination and survival of commercial wine yeast in the vineyard: a large-scale, three years study. FEMS Yeast Res 5, 959-969.

Villa-Carvajal, M., Querol, A. and Belloch, C. (2006) Identification of species in the genus Pichia by restriction of the internal transcribed spacers (ITS1 and ITS2) and the 5.8S ribosomal DNA gene. Antonie Van Leeuwenhoek 90, 171-181.

White, T.J., Bruns, T., Lee, S. and Taylor, J.W. (1990) Amplification and direct sequencing of fungal ribosomal RNA genes for phylogenetics. In PCR Protocols: A Guide to Methods and Applications, ed. Innis, M.A., Gelfand, D.H., Sninsky, J.J. and White, T.J. pp. 315-322. New York: Academic Press. 